\title{
Crise do capital e precarização do trabalho: o Brasil em tempos de Covid-19
}

\author{
Cláudia Maria Costa Gomes ${ }^{1}$ \\ Fabiana Alcântara Lima² \\ Liana Amaro Augusto de Carvalho ${ }^{3}$
}

\begin{abstract}
Resumo
O artigo apresenta uma análise da teoria da crise, tomando como referência metodológica a formulação teórica de Marx sobre a lei tendencial à queda da taxa de lucro, partindo da suposição que a precarização do trabalho é um fator contrarrestante. No plano empírico, apresentamos dados que atestam os impactos da crise agravada pela Covid-19 no aumento do exército de reserva, incidindo na potencialização do grau de exploração da força de trabalho no Brasil. Nossa argumentação sugere que as medidas emergenciais do governo Bolsonaro são inócuas para impedir o avanço da crise. Por tratar-se de um ensaio, as reflexões no decorrer do texto instigam os leitores a tirar suas próprias conclusões.

\section{Palavras-chave}

Crise do capital; Precarização do trabalho; Pauperismo; Covid-19. Capitalismo brasileiro.
\end{abstract}

\section{Capital crisis and labor preacarization: Brazil in COVID-19 times}

\begin{abstract}
The article presents an analysis of the crisis theory, taking as a methodological reference Marx's theoretical formulation on the law that tends to fall in the profit rate, based on the assumption that precarious work is a counter-factor. At the empirical level, we present data that attest to the impacts of the crisis exacerbated by Covid-19 on the increase of the reserve army, focusing on the enhancement of the degree of exploitation of the workforce in Brazil. Our argument suggests that the Bolsonaro government's emergency measures are harmless to prevent the crisis from advancing. As this is an essay, reflections throughout the text prompt readers to draw their own conclusions.
\end{abstract}

\section{Keywords}

Crisis of capital; Precarious work; Pauperism; Covid-19; Brazilian capitalism.

Artigo recebido em junho 2020

Artigo aprovado em agosto de 2020 


\section{Introdução}

A contribuição originária de Marx sobre as crises não se encontra sistematizada em um texto determinado, radica no seu procedimento explicativo lógico e histórico da tendência geral do desenvolvimento do capitalismo, anunciada no prefácio à primeira edição de O Capital, como leis e tendências próprias que "operam e se impõe como uma necessidade férrea” (MARX, 2002, p. 16). Todo seu esforço se concentra na compreensão da dinâmica do capitalismo, de suas contradições, das tendências e contratendências através da análise rigorosa das relações sociais complexas entre a superestrutura da vida social com o modo dominante de produção.

Em razão dos limites do artigo, não iremos expor a complexidade e controvérsia do rico debate sobre o tema ${ }^{4}$. Faremos apenas um ensaio que expressa uma linha de investigação aberta pelos nossos estudos $^{5}$. Aqui o objetivo é apontar alguns elementos sobre a precarização do trabalho, tomando como referência as leis que regem a acumulação capitalista, para explicar a conjuntura de crise acelerada pela pandemia da Covid-19 e os impactos para a classe trabalhadora brasileira. A suposição é de que a resseção provocada pela crise de 2008 se amplia com a generalização da Covid-19 e provoca um aumento do exército de reserva, acelerando o grau da precarização do trabalho, que se constitui como um fator contrarrestante à queda da taxa de lucro à medida que provoca não só uma redução do preço e valor da força de trabalho, mas transforma uma parte da população ocupada em excedente, através do desemprego aberto, fomentando, assim, o pauperismo.

Partimos da análise teórica marxiana acerca da lei do valor para explicar tanto a natureza do capitalismo quanto suas crises e chegamos ao argumento de que a sua deflagração só pode ser compreendida como resultado das contradições do processo de acumulação capitalista que tem como base a exploração do tempo de trabalho excedente com vistas ao incremento de mais-valia. E sem 
situar o capitalismo per si como um sistema de exploração e dominação mundial, não se pode entender sua fase atual e, muito menos, compreender que a condição da classe trabalhadora está diretamente atrelada à lei geral da acumulação capitalista, cujo grau de sua reprodução enquanto classe e parcela do produto de seu trabalho, expresso na forma de salário direto, indireto (saúde, educação, etc.,) e deferido (aposentadorias e pensões), está cada vez mais limitado pela continuidade do processo de acumulação. O fato é que "estamos diante de um formidável impulso da acumulação capitalista, a cada dia mais destruidor" (FONTES, 2008, p. 33).

Em nível da conjuntura, podemos dizer que a crise da Covid-19 aprofunda a larga depressão do século XXI (ROBERTS, 2020) que se arrasta desde 2008 e assola a economia mundial. À vista disso, antecipa-se na periferia do capital uma política econômica de mais austeridade, projetando além de tudo, a ilha da fantasia dos ativos financeiros cada vez mais caros e financiados por interesses supostamente duvidosos para movimentar a acumulação. Se nas principais economias capitalistas do mundo, as intervenções para conter a pandemia se deram com forte intervenção estatal ao estilo New Deal ${ }^{6}$, através do aumento com gastos em saúde, renda universal básica para socorrer os desempregados e subsídios monetários para as empresas; na América latina, com destaque para o Brasil, o enfrentamento da pandemia deixa um rastro de devastação econômica e social sem precedentes, considerando que o desmonte do SUS e do SUAS jogam água no moinho da tragédia anunciada desde o epicentro da pandemia na China e na Europa.

Ademais, a opção da política de Estado do governo Bolsonaro tem levado as classes subalternas a uma situação dramática de enfrentamento da pandemia. Submetidos à informalidade e a precarização laboral, ao desemprego aberto, a péssimas condições habitacionais e sanitárias, alimentação e vida, muitos trabalhadores somam-se às fileiras das estatísticas de mortalidade e pauperização crescentes. 


\section{Crise e acumulação capitalista}

As crises não são uma exceção na dinâmica capitalista. É explicada pela fase de acumulação que a precede. Sua possibilidade de deflagração está contida desde o nível mais abstrato até o mais concreto no processo de desenvolvimento da economia capitalista. A contradição entre produção e consumo, gerada por meio da anarquia da produção, origina um processo cumulativo de tensões que se resolve nas crises econômicas. À vista disso, no centro nevrálgico da crise encontra-se a acumulação de capital, que por sua vez incide na aplicação da mais- valia para a ampliação e reprodução do processo produtivo que se dá através da compra de meios de produção e força de trabalho de modo imperativo. Isto quer dizer, que a acumulação para se realizar, necessita que uma parte da mais-valia seja consumida produtivamente. À vista disso, a pulsão à valorização do capital nunca tem limites, resulta sempre na busca por massas de capitais cada vez maiores à custa de rapinagem e expropriações que se agigantam sob a classe trabalhadora e a vida social de maneira cada vez mais avassaladora (COMES, 2020). E a hodierna crise mundial, acelerada pelas condições da pandemia da Covid-19, tenciona o capital a aumentar a exploração da força de trabalho para restaurar os lucros e recolocar em marcha a acumulação, estagnada pela magnitude e avanço da larga depressão aberta desde 2008, o qual reflete profundamente as dificuldades crescentes de valorização do capital na esfera produtiva.

A lei tendencial a queda da taxa de lucro ${ }^{7}$, que está subscrita no livro III de O Capital é no âmbito da teoria do valor, uma das mais importantes para a análise das crises, pois revela a forma invisível e contraditória da acumulação. Como se sabe, a mais-valia é a procedência singular do lucro, forma-se a partir do capital variável e não do capital constante. Sendo assim, a taxa de lucro é igual à razão entre a mais-valia e a soma dos capitais constante e variáveis, ou o total do capital adiantado. É precisamente na concorrência intercapitalista, re- 
gida pela maximização da rentabilidade (acréscimo da taxa de lucro), que os capitalistas procuram aumentar a produtividade, substituindo força de trabalho por meios de produção. Essa substituição provoca um aumento na composição do capital e vai produzir efeitos no sentido de dificultar cada vez mais a valorização do capital (só possível de se obter por meio da força de trabalho).

Pode-se dizer de modo muito generalizado, que a tendência ao declínio da taxa de lucro se realiza por meio da elevação da produtividade social do trabalho e o correlato aumento da composição orgânica do capital. Para usar os termos do próprio Marx, isso quer dizer que o capital constante (c) cresce mais rápido que o capital variável (v). E o aumento da composição orgânica do capital (c/v), sempre tende a diminuir a taxa de lucro $\left(l^{-}=\mathrm{m} / \mathrm{c}+\mathrm{v}\right)$ : onde l' é a taxa geral de lucro; $m$ a massa de mais-valia produzida; c o capital constante e $\checkmark$ o capital variável. Se dividirmos o numerador e o denominador por v teremos: $\left.\left.I^{\prime}=(\mathrm{m} / \mathrm{v}) /[\mathrm{c} / \mathrm{v})\right]+(\mathrm{v} / \mathrm{v})\right]$ e portanto, $I^{\prime}=\mathrm{m}^{\prime} /\left(\mathrm{o}^{\prime}+1\right)$, onde $\mathrm{m}^{\prime}$ é a taxa de mais-valia ou de exploração e ó, a composição orgânica do capital (CARCANHOLO, 2013).

Visto dessa perspectiva, o desenvolvimento do processo produtivo ao aumentar a composição orgânica do capital determina uma valorização incessante como movimento em si da própria reprodução do capital, que tem sua substância na extração do valor excedente da força de trabalho. Isso significa que nas crises a tendência do capital é aumentar a taxa de mais valia, mediante a desvalorização da força de trabalho, a qual incide sobre os salários, a jornada de trabalho, o grau de exploração da força de trabalho e o aumento do exército de reserva. Porém, a elevação progressiva da composição do capital social produz um efeito paradoxal e encontra um limite na lei decrescente da taxa de lucro.

Isso quer dizer que os problemas gerados no interior do próprio regime de acumulação motivam uma predisposição inexorável às crises, a partir da tendência declinante da taxa média de lucro. Esse pro- 
cesso se determina como tendência contraditória, afetando, com isso, a própria força motriz da acumulação e, assim, seu desenvolvimento histórico, ocasionando, "especulação, crises, capital supérfluo ao lado de população supérflua” (MARX, 1998, p. 174).

Marx explica que a tendência ao declínio da taxa de lucro, pode ser operada também por contratendências, considerando que a pressão e o descenso podem ser neutralizados por diversos fatores, evitando assim uma queda total. Os fatores que operam como causas contrarrestantes, são: i) aumento do grau de exploração do trabalho; ii) redução do salário relativo (proporção entre salário real e a produtividade); iii) baixa do preço dos elementos do capital constante; iv) superpopulação relativa; v) comércio exterior; vi) aumento do capital por ações. Esses fatores retardam temporariamente a ação absoluta da referida lei, mas recolocam a contradição em um nível sempre mais difícil de ser resolvido.

Nesse sentido, as causas contrarrestantes são mecanismos da própria lei geral da acumulação, que atuam como tendência progressiva para interferir nas contradições da composição orgânica do capital e nas dificuldades cada vez mais crescentes de valorização. Portanto, atuam para aumentar a exploração da força de trabalho, mediante a extração da mais valia absoluta (redução de salário e intensifıcação da jornada de trabalho) e a mais valia relativa (determinação do salário, tomando como fixas as necessidades de consumo dos trabalhadores). Todo esse processo provoca uma brutal degradação das condições de vida da maioria da classe trabalhadora, que se impõe ante a crise, evidenciando a tendência histórica do capitalismo.

Essa rápida exposição teórica é particularmente importante para explicar por que o capitalismo atualmente está imerso em uma grande depressão ${ }^{8}$, apesar da oligarquia financeira mundial e das grandes quantidades de dinheiro em circulação. O que se observa é que os efeitos da crise em escala mundial assinalam as limitações das economias imperialistas em manter sob controle as taxas de crescimento e 
rentabilidade, capazes de garantir um ritmo de acumulação ascendente, expansivo e concentrado desde 1970 (ARRIZABALO, 2016).

Nem mesmo a resposta à crise, pelas frações de classe do capital imperialista, através de duas décadas de ajuste neoliberal e batalha do capital pela expropriação/desvalorização da força de trabalho, foi suficiente para garantir um largo período de recuperação e crescimento. Ao contrário, os dados atestam que entre 2003-2008 chegou-se ao fim uma fase expansiva das taxas de lucro da economia mundial, em função da desaceleração da economia chinesa. Segundo Maito (2013, p. 150-151), "[...] a taxa de lucro ponderada da economia mundial sem a China foi de $16,4 \%$, e com a China $21 \%$. A taxa de lucro da China caiu de $31,8 \%$, em 2008 , para $20 \%$, em 2009 , o que contribuiu para a queda da taxa global para 16,5\% com a China e 15,6\% sem ela".

Particularmente, no ciclo de acumulação financeira ${ }^{9}$, esta queda expressa a contradição produção/apropriação, provocada pela insuficiente capacidade do capital produtivo gerar o necessário excedente econômico para atender às exigências do capital especulativo ${ }^{10}$, repercutindo, em grande magnitude, na elevação do grau de exploração da força de trabalho (LIMA, 2012).

Portanto, a saída do capitalismo para se liberar das esferas improdutivas e menos produtivas do capital, ao buscar criar condições inovadoras para iniciar uma nova fase de crescimento, através da financeirização, demostrou-se impresumível, considerando que a recuperação da crise de 2008 se produziu de maneira muito limitada com um pífıo crescimento do PIB mundial de 2\% (BPI, 2014) ${ }^{11}$. Isso explica a necessidade cada vez maior de desvalorização e exploração da força de trabalho e a total destruição dos direitos e garantias sociais, resultado das conquistas democráticas e das lutas dos trabalhadores.

E por aqui se esclarece que a crise acelerada pelo COVID-19, implicará em uma regressão social sem precedentes que já vinha crescendo de forma assaz desde a grande depressão de 2008. Por isso, o mais provável é que esta epidemia aumente o exército de reserva e 
com isso, a pauperização e a desigualdade no mundo, tendo em vista a forte caída do PIB mundial em 2020 que colapsa a níveis comparados a segunda guerra mundial (ROBERTS, 2020).

Na América Latina, os efeitos da crise provocados pela pandemia são demolidores, múltiplos e conflituosos. A previsão da CEPAL é que a atividade econômica da região sofra uma retração em 5,3\% em 2020, com efeitos negativos para o mercado de trabalho e "projeta um aumento da taxa de desocupação de menos 3,4\% até alcançar uma taxa de $11,5 \%$, o que equivale a mais de 11,5 milhões de novos desempregados" (CEPAL, 2020, p.5, tradução nossa).

Essas determinações reproduzem e aprofundam a dependência e a crise no subcontinente, criando assim uma forte instabilidade econômica, política e social e mais contrarreformas conduzidas pelos Estados. É até presumível que "decidam enfrentar suas "dívidas da epidemia" negociando com o FMI e retornando a suas políticas anteriores de austeridade fiscal, com a venda acelerada de seus patrimônios públicos na "bacia das almas", para poder "pagar as contas" deixadas pelo coronavírus", como diz Fiori (2020, p.3).

O enfrentamento da pandemia pelo Estado brasileiro se confronta com o ajuste neoliberal e as medidas de austeridade fiscal nos últimos anos, com cortes nas despesas com políticas sociais e investimentos públicos em serviços sociais, flexibilização do mercado fınanceiro para a presença de bancos internacionais, programa de privatizações, desregulamentação das relações trabalhistas, sistema previdenciário, entre outros que expressam as contrarreformas.

No Brasil, esse quadro, como sinalizado, se agudiza em função da desigualdade social e da crise política, num governo que escolhe a economia em detrimento da vida. Alguns elementos aprofundam a crise no Brasil: as transformações no mundo do trabalho levando a um trabalho absoluta e amplamente precarizado, e o crescimento significativo do setor de serviços (incluindo o comércio), que hoje emprega mais de $50 \%$ da força 
de trabalho. Esses são dois elementos que estruturam as relações sociais e de trabalho de forma mais favorável à acumulação (PINTO; CERQUEIRA, 2020, p.43).

Em última instância, isso explica a necessidade cada vez maior de desvalorização e exploração da força de trabalho e a total destruição dos direitos e garantias sociais, resultado das conquistas democráticas e das lutas dos trabalhadores no último século, implicando uma regressão social sem precedentes.

\section{Precarização do Trabalho e aumento do exército de reserva no Brasil}

Em termos empíricos, no Brasil, como no resto da América Latina, os dados confirmam, de maneira inequívoca, a recessão econômica provocada pela crise e a resposta do capital para a retomada das taxas de lucros, que tem na crescente desvalorização da força de trabalho, o objetivo central, realizada nos últimos anos por meio de políticas econômicas de ajuste e contrarreformas, a qual incide sobre o barateamento da mercadoria força de trabalho, em termos de preço e valor.

Seu empobrecimento relativo é uma exigência do processo de acumulação, expresso pelo aumento da taxa de mais-va $\neg$ lia, da exploração. Contudo o que está sendo proposto agora não é esse empobrecimento relativo, mas um empobrecimento absoluto, a expressão final da destruição das forças produtivas para as quais as políticas e ações do capital e de suas instituições fluem cada vez mais (ARRIZABALO, 2020, p.55).

E os dados são incontestáveis. A Pesquisa Nacional por Amostra de Domicílios Contínua (Pnad Contínua), do Instituto Brasileiro de Ceografia e Estatística (IBCE, 2020) revela que, somente no primeiro trimestre de 2020 a taxa de desemprego aumentou de $11,2 \%$ para $12,6 \%$, correspondendo a 900 mil vagas de emprego suprimidas, frente ao trimestre anterior. Com isso, o Brasil eleva a um patamar 13 milhões de pessoas desempregadas, sendo 4,8 milhões de trabalhadores que se 
somam a população supérflua, excedente, no entanto, não contabilizados nos dados oficiais do desemprego ${ }^{13}$.

Importa destacar que do total da população ocupada brasileira, cerca de 40\% é informalizada, trata-se de 39,5 milhões de trabalhadores à margem do sistema de proteção social. Ainda de acordo com o IBCE (2020), o contingente de trabalhadores informais apresentou uma tímida queda (1,1\%), caindo de 41\% para 39,9\% em relação ao último trimestre, provavelmente ocorrido à custa do aumento da taxa de subocupação, que avançou 5,6\%, o que corresponde a 1,5 milhão de pessoas a mais trabalhando sob condições precárias. Estamos nos referindo aos trabalhos intermitentes, uberizados, prestadores de serviços, temporários, por conta própria e autônomos (não formalizados), que nos últimos cinco anos têm ocultado os índices de informalidade no país, mas não diminuíram o grau de desproteção social e degradação do trabalho.

Em nível mundial, no último estudo conjunto realizado pela CEPAL e a Organização Internacional do Trabalho (OIT) $)^{14}$, as projeções para os países da América Latina e do Caribe também confirmam nossas suposições, considerando que nesses países a taxa média de informalidade é de aproximadamente 54\%. Estima-se que cerca de 1,6 bilhão de trabalhadores informais podem perder seus meios de sustento, índice que representa quase a metade da força de trabalho informalizada do mundo (entre os 3,3 bilhões de trabalhadores em nível mundial, cerca de 2 bilhões se encontram na informalidade (OIT, 2020) ${ }^{15}$.

Com a crise acelerada pelo Covid-19, o capital reitera as medidas de ajuste neoliberal que já vinham em processo enquanto alternativa à saída da crise. As reformas laborais e previdenciárias no Brasil representam essa tendência de pilhagem neocolonial e faz com que as políticas voltadas ao trabalho e a renda se tornem o epicentro do debate, sob a orientação dos organismos financeiros internacionais, que explicitam cada vez mais abertamente seus interesses, apontando "medidas para o mercado de trabalho, que contribuam para reduções 
adicionais nos custos do trabalho" (COMISSÃO EUROPEIA, 2012, p. 71, tradução nossa $)^{16}$, os quais incidem sobre os salários.

Ainda no documento da CEPAL e OIT (2020) citado anteriormente, para um amplo setor da população trabalhadora precarizada e informal, as Nações Unidas (2020) têm recomendado como medidas imediatas à crise acelerada pela Covid-19 i) o apoio dos serviços de proteção social básica e ii) a proteção das pequenas e médias empresas e dos trabalhadores da economia informal através de incentivos financeiros. No Brasil, seguindo esse receituário, o governo Bolsonaro regulamentou o Programa Nacional de Apoio às Microempresas e Empresas de Pequeno Porte (PRONAMPE) ${ }^{17}$. O público alvo a ser atingido pelo programa são as pequenas e microempresas com faturamento de $\mathrm{R} \$ 360$ mil a $\mathrm{R} \$ 4,8$ milhões por ano (PORTAL EMPREENDEDOR, 2020). Esse programa não contempla Microempreendedores Individuais (MEIs), cujo faturamento é expressivamente menor, até $\mathrm{R} \$ 60$ mil, podendo contratar até um funcionário; são os chamados trabalhadores por conta própria, fortemente atingidos pela crise atual, cujos índices de formalização são ainda muito baixos. Ainda que as estatísticas recentes evidenciadas no Portal do Empreendedor (2020) ${ }^{18}$ sinalizem uma elevação do número de registros de MEls no país, (cerca de 10 milhões) observa-se um abismo em relação ao total de trabalhadores por conta própria (23,4 milhões), o que revela a reprodução da informalidade em grande escala.

Nas palavras de Tavares (2004), trata-se de formas de trabalho que se articulam por fios invisíveis à produção formal numa relação de assalariamento disfarçado - uma desigualdade estrutural metamorfoseada em igualdade individual - que esbarra nas determinações estruturais do sistema. Seduzidos pela ideia de subsistirem como "dono do seu próprio negócio" ao estilo shumpeteriano ${ }^{19}$, muitos trabalhadores, em escala individual, passam a redefinir a sua personalidade jurídica ao registrarem uma empresa em seu nome, assumindo a responsabilidade com encargos sociais e custos relacionados a compra de mercadorias, meios e objetos de produção. 
Ganha centralidade a figura do infoproletariado/cibertariado/proletariadodigital, que por meio do trabalho remoto, acelera a produtividade do trabalho em grau extremo, instituindo o home office, o teletrabalho, dentre outras formas mediadas pelas plataformas digitais como imperativo de sobrevivência do capital, a exemplo do emblemático serviço dos entregadores, cujas condições de trabalho traduz o que Antunes (2018) convencionou denominar de escravidão moderna na era digital.

Nesse sentido, a crise repõe à ordem do dia novas faces da precarização do trabalho, em que o aumento da mais-valia relativa e o rebaixamento dos salários são reeditados enquanto respostas à tendência da queda da taxa de lucro, potencializando a desvalorização sistemática da força de trabalho e tornando excedente uma parte da população trabalhadora (desempregada ou submetida a trabalho em tempo parcial, intermitente e a ocupações com baixa remuneração).

São os trabalhadores sem direitos sociais dos mais diversos aplicativos como Uber, Rappi, iFood, as empregadas domésticas, os ambulantes, ou seja, de $40 \%$ a $50 \%$ dos trabalhadores e trabaIhadoras que vivem na informalidade ou em relações de trabalho (proteção social) fragilizadas (LARA, 2020, p. 62).

Nesta situação de pandemia, em que o universo digital aparece como alternativa ao isolamento social, muitos trabalhadores acabam sendo "empreendedores de si mesmos"; sem relação patronal, sem propriedade dos meios de produção, com jornadas exaustivas e salários rebaixados (pagos por peça), algumas vezes, transformados em dívida. Mesclam-se múltiplas faces da informalidade e precarização do trabalho, situadas, predominantemente, na esfera da circulação e na dinâmica de venda de serviços e mercadorias, enquanto potencial meio de apropriação de valor, cuja natureza se funda, de modo insubstituível, na produção de excedente capitalista (CARCANHOLO \& NAKATANI, 2015). 
Socialmente, tudo isso se expressa não só pelos limites de acesso ao trabalho, mas a um aumento exponencial do pauperismo das classes trabalhadoras, alavancando a um só tempo a acumulação do capital e ampliando o exército de reserva, compelindo milhares de trabalhadores informais ou completamente desempregados, a aceitar qualquer forma de trabalho ou engrossar as fileiras para o acesso aos programas de renda mínima, enquanto último refúgio de sobrevivência.

\section{Pauperismo, Covid-19 e auxílio emergencial no Brasil}

É decisivo recordar que o exército industrial de reserva tem uma utilidade concreta para a acumulação: "proporciona o material humano a serviço das necessidades variáveis de expansão do capital e sempre pronto para ser explorado" (MARX, 2002, p. 735). O capital expulsa força de trabalho do âmbito produtivo, mas a um nível que não comprometa a produtividade do capital mediante a incorporação de novas tecnologias. Por isso, ao passo que se dispensa força de trabalho inserida no processo de produção, abrem-se as brechas para a produção de uma população sobrante em face das necessidades do capital (CARVALHO, 2014).

Deduz-se, portanto, que o pauperismo se constitui como expressão do desenvolvimento do capital e está diretamente relacionado aos níveis de acumulação, de forma que a demanda de força de trabalho é regulada por esta. E tal como havíamos indicado, em conjunturas desfavoráveis, na qual a taxa média de lucros entra em estagnação ou queda, o capital expulsa força de trabalho dos seus postos, substituindo-os por tecnologias. O efeito causado é sofrido por aqueles que permaneceram absorvidos como força de trabalho no mercado, pois se trata de aumentar a intensidade da jornada para compensar a produção do excedente de valor (CARVALHO, 2014). Ainda, o aumento do desemprego parece contribuir para uma maior precarização das condições de vida, aprofundando os índices de desigualdade no país, agravados pelo déficit histórico nas garantias dos direitos sociais fundamentais, como saúde, educação, moradia, trabalho e renda. 
Como afirmamos anteriormente, a pandemia do Covid-19 assinala um período de maior recessão mundial desde a crise de 2008, com impactos sociais que se evidenciam de maneira brutal nos países periféricos. Desde 2014 as informações publicadas pela CEPAL (2019), já indicavam um aumento sensível do empobrecimento na América Latina e no Caribe, que numa escala crescente até 2019 sinalizava o aumento de aproximadamente três pontos percentuais de pobreza e quatro de pobreza extrema, o que equivale ao acréscimo aproximadamente de vinte sete milhões de pessoas em cada um dos substratos supracitados, totalizando cerca de cinquenta milhões de pessoas na linha de pobreza e abaixo dela, segundo seus próprios termos ${ }^{20}$.

No Brasil, o IBGE (2019) atestou que, seguindo a tendência apontada na região, os níveis de empobrecimento da população brasileira no período analisado subiram, de fato. De acordo com as informações socializadas ${ }^{21}$, em 2018 aproximadamente 52,5 milhões de brasileiros estavam alinhados ao contingente pobre do país, e mais 13,5 milhões de pessoas na linha de pobreza extrema. Deste quantitativo, em torno de um milhão de pessoas despencou do primeiro para o segundo contingente, engrossando as fileiras dos paupéries do país. Certamente, na conjuntura brasileira as expressões de crise econômica somaram-se a uma conjuntura política conflituosa ${ }^{22}$ canalizando para a ampliação dos processos de empobrecimento, tendo como efeito a recomposição do exército industrial de reserva a qual incorporou parte da chamada "nova classe média"23.

Em 2020 as tensões econômicas que se desenhavam no cenário mundial parecem ter tomado proporções assustadoras com a crise sanitária desencadeada pela pandemia do COVID-19, da qual o Brasil se tornou o epicentro em curtíssimo tempo, causando a morte de milhares de brasileiros, predominantemente, negros e pobres, que se concentraram na vanguarda das estatísticas, o que ressalta o caráter de classe, gênero e raça da pandemia em um país onde 11,4 milhões vivem em aglomerados subnormais, favelas e assentamentos precários (IBCE, 
2010). Todas as agências multilaterais estimam que a crise acarretará amplas implicações negativas para o desenvolvimento econômico e social da região. Isto porque, além do baixo crescimento econômico previsto em 2020 com uma queda no PIB de 5,3\% segundo dados da CEPAL (2020), a desigualdade e a vulnerabilidade social certamente serão potencializadas, desencadeando uma tendência crescente de aprofundamento do empobrecimento, alcançando 8,8 milhões de trabalhadores (OIT, 2020). No Brasil, apesar de não ter dados conclusivos sobre a profundidade e largura das consequências de tal crise, sabemos que os setores mais atingidos estão entre trabalhadores já precarizados e sem direitos, como assinalamos, anteriormente. E foram justamente, "esses trabalhadores que lotaram as filas da Caixa Econômica Federal em busca dos R\$600,00” (LARA, 2020, p. 62).

Como se sabe, o governo Bolsonaro estabeleceu a concessão de um auxílio de caráter emergencial pelo período máximo de três meses, com a transferência de renda individual com valores mensais entre $\mathrm{R} \$ 600,00$ e $\mathrm{R} \$ 1.200,00$ por família, para aqueles que, em razão do isolamento social decretado nos estados e municípios brasileiros, pudessem sobreviver, uma vez que supostamente estariam impossibilitados de trabalhar. Nesse sentido, compreendemos que o auxílio emergencial no Brasil instituído pela Lei 13.982/2020, mantém a função de manutenção da reprodução de força de trabalho próxima de níveis mínimos, considerando como público beneficiário os trabaIhadores desempregados, intermitentes, informais, aqueles inscritos no Cadastro Único para Programas Sociais do Governo Federal, bem como os trabalhadores por conta própria, dentre os quais destacamos anteriormente, os microempreendedores Individuais (MEIs) ${ }^{24}$.

O que este contingente tem em comum não é apenas a ampla exploração da sua força de trabalho e a desproteção indiscutivelmente alarmantes, mas o fato de que nele a renda, enquanto fluxo monetário aparece como uma incerteza diária, sendo determinada pelo andamento da demanda cotidiana. Outrossim, como um agravante, na 
situação de crise agudizada pela COVID-19, este contingente passou a engrossar direta ou indiretamente as filas da desocupação, somando-se a estes os dispersos pela insolvência de pequenas e médias empresas, e ficou à mercê de medidas implementadas pelo Estado Brasileiro como estratégia de enfrentamento, que se alinha a outras iniciativas emergenciais de auxílio na mesma região.

Obviamente, por se tratar de uma iniciativa emergencial, o auxílio não se inscreve como um programa de transferência de renda, uma vez que foi pensado para viger apenas enquanto durar a crise sanitária causada pelo novo Corona Vírus, como um benefício financeiro, e não chega a configurar um fluxo monetário. Nesse sentido, como estratégia de política econômica, o auxílio emergencial tem como objetivo impactar os níveis crescentes de desemprego em massa pela pandemia do Covid-19. Sob esse aspecto, arriscamos afirmar que se trata de um mecanismo contratendencial ao interferir na composição do exército de reserva.

Diante do contexto alarmante em todo o mundo deflagrado pela crise econômica seguida da sanitária, propostas de renda básica universal têm se recolocado como uma solução inovadora para remediar os efeitos inextrincáveis do capitalismo, como se fosse possivel resolver as consequências das relações sociais que o baliza num passe de mágica.

No Brasil, seguindo essa tendência, embora se contrapondo a medidas desse tipo, o governo federal tem indicado a tendência à supressão de programas de transferência como o Bolsa Família para estabelecer outro como a sua marca de governo. Entretanto, entendemos que propostas como estas indicam "ma troca de seis por meia dúzia", dando consecução a uma ideia que já está em pauta desde muito tempo antes do Bolsa Família se tornar o carro chefe do enfrentamento ao pauperismo no país.

Como a realidade tem demonstrado, medidas como estas são absolutamente ineficazes em relação à reprodução do pauperismo relativo e absoluto nesse país. Ainda que possa oferecer imediatamente e 
por um curto espaço de tempo uma possibilidade de enfrentamento das expressões de avanço da crise, não operam mudanças substantivas no cotidiano das famílias beneficiadas, proporcionando apenas o alívio das suas expressões mais flagrantes diante da precarização do trabalho e do desemprego aberto, como a fome.

\section{Considerações Finais}

Seguindo Marx, expomos aqui algumas categorias da lei tendencial à queda da taxa de lucro, para explicar a crise capitalista, de modo que pudéssemos analisar a manifestação delas no contexto da pandemia do Covid-19 na particularidade do Brasil.

É fato inconteste que as crises são funcionais ao modo de produção capitalista. O seu objetivo é manter a lógica de funcionamento intocável, como condição de autoconservação. Portanto, aumentar a produtividade social do capital é meio para que se obtenha uma taxa cada vez maior de lucro, através do aumento da taxa de mais-valia. Essa é a alavanca mais poderosa da acumulação.

No artigo, ao procuramos demonstrar o caráter tendencial do capital na busca crescente por lucros, que opera por meio de oscilações e irregularidades, (contratendências que lhes são intrínsecas), aventamos a suposição de que a precarização do trabalho, se constitui como um fator contrarrestante à queda da taxa de lucro à medida que provoca não só uma redução do preço e valor da força de trabalho, mas transforma uma parte da população ocupada em excedente, através do desemprego aberto.

Com essa linha de argumentação, apontamos que a composição orgânica do capital, tem sua substância na extração do valor excedente da força de trabalho. Nessa dinâmica, procuramos demonstrar através dos dados de realidade como a classe trabalhadora assume a responsabilidade dos custos e condições do trabalho, cada vez mais precário e desprotegido, cujas consequências destrutivas é uma maior subsunção do trabalho ao capital, que para se valorizar, necessita re- 
duzir seus investimentos em capital variável e transferir parte dos custos com capital constante para o trabalhador.

Com esforço de síntese, analisamos o contexto brasileiro à luz das tendências apontadas por Marx para explicar a crise e a resposta do Estado frente às suas expressões. Sem contar que todos os indicadores sociais, registram o aumento do desemprego que levará a uma maior precarização das condições de vida, aprofundando os índices de desigualdade no país, agravados pelo déficit histórico nas garantias dos direitos sociais fundamentais, como saúde, educação, moradia, trabalho e renda.

Como se depreende do que foi tratado até aqui, concluímos que este contingente não tem apenas em comum a ampla exploração da sua força de trabalho e a desproteção indiscutivelmente alarmantes, mas o fato de que nele a renda, enquanto fluxo monetário, aparece como uma incerteza diária, considerando que muitos estiveram à mercê das inócuas medidas implementadas pelo Estado Brasileiro.

Ao fim e ao cabo, a saída da crise revela-se implacável. O que visto em termos de capital em seu conjunto, evidencia o esforço para o rebaixamento do custo da força de trabalho. Esforço que abrange as diversas formas de terceirização e de desregulamentação da relação capital-trabalho, com redução de direitos trabaIhistas, cujos custos fazem parte do capital variável e a redução da necessidade de repartição da mais-valia com o Estado, por meio de ajustes e medidas cada vez mais austeras (FRANCO, 2019).

\section{Referências}

ANTUNES, Ricardo (org.). Proletariado digital, serviços e valor. Riqueza e miséria do trabalho no Brasil IV. 1 ed. São Paulo: Boitempo, 2018.

ARRIZABALO, M. Xabier. Capitalismo y Economía Mundial: bases teóricas y análisis empírico para la comprensión de los problemas económicos del siglo XXI. 2. edición, Instituto Marxista de Economía (IME), Madrid, 2016. 
ARRIZABALO, M. Xabier. Imperialismo, destruição das forças produtivas e crise crônica do capitalismo: o Capital, um instrumento essencial para entender a atual economia mundial In: A Crise e os limites históricos do capitalismo (org.) Cláudia M. C. Gomes. $1^{\text {a }}$ ed. Curitiba, Editora Appris, 2020. pp. 28-86.

BANCO MUNDIAL. A economia em tempos de Covid-19: relatório semestral sobre a região da América Latina e Caribe. 2020. Disponivel em: https:// openknowledge.worldbank.org/handle/10986/33555. Acesso em 8 jun. 2020.

CARCANHOLO, Reinaldo A. NAKATANI, Paulo. O capital especulativo parasitário: uma precisão teórica sobre o capital financeiro, característico da globalização. In: Especulação e lucros Fictícios. Helder Gomes (org.). 1 ed. São Paulo: Outras expressões, 2015.

CARCANHOLO, Reinaldo A. La ley de la baja tendencial de la tasa de ganancia. Revista “Laberinto" n. 38, 2013, 15 p. (27-41).

CARVALHO, Liana Amaro Augusto de. Os impactos do programa bolsa familia sobre a pobreza absoluta e relativa no Brasil. Dissertação de Mestrado em Políticas Sociais. João Pessoa, Universidade Federal da Paraíba, 2014.

CEPAL. Comisión Económica para América Latina y el Caribe. Panorama Social de América Latina. Santiago: CEPAL, 2019. Disponível em: https://repositorio.cepal.org/bitstream/handle/11362/44969/5/S1901133_es.pdf. Acesso em 5 jun. 2020.

CEPAL. El desafío social en tiempos del COVID-19. Informe Especial COVID-19, $\mathrm{N}^{\circ}$ 3. 2020. Disponível em: cepal.org/bitstream/handle/11362/45527/5/ S2000325_es.pdf. Acesso em 12 jun. 2020.

FIORI, J. Luís. O vírus, o petróleo e a geopolítica mundial. Disponível em: https://www.sul21.com.br/opiniaopublica/2020/04/o-virus-o-petroleo-e-a-geopolitica-mundial-por-jose-luis-fiori/. Acesso em: 10 jun.2020.

FRANCO, David Silva. Uberização do Trabalho e acumulação capitalista. Cad. EBAPE. BR, v. 17, Edição Especial, Rio de Janeiro, Nov. 2019.

FONTES, Virginia. Capitalismo, imperialismo, movimentos sociais e lutas de classe. Em Pauta, n. 21, Rio de Janeiro. Ed. UERJ, 2008, p. 23-36.

GOMES, Cláudia. M. C. Por uma Teoria do Capital: Dependência e desenvolvimento econômico brasileiro no contexto da crise. 102f. Relatório Final de Pesquisa (Pós-doutorado em Economía Internacional y Desarrollo). Departamento de Economía Aplicada I, Universidad Complutense de Madrid, 2020. 
IBCE. Síntese de indicadores sociais 2019. Disponivel em: https://agenciadenoticias.ibge.gov.br/media/com_mediaibge/arquivos/f1404e8068f13a84a53a9d0b7ca997e3.pdf. Acesso em18 jun. 2020.

KLIMAN, Andrew J. Harvey contra Marx debate con, HARVEY, David, 2014 - 2017, disponible en: https://encuentrocomunista.org/boletin/boletin-rojo-14-septiembre-2017/. Acesso em: 05 jun. 2019.

LARA, Ricardo. Pandemia e capital: as repercussões da Covid-19 na reprodução social. In: Revista Libertas / Universidade Federal de Juiz de Fora, Programa de Pós-graduação em Serviço Social, Curso de graduação em Serviço Social. - n.1 (abril, 2001), Juiz de Fora, 2020. p. 53-69.

LIMA, Fabiana Alcântara. Crise contemporânea, microcrédito e trabalho informal: uma análise da tendência desenvolvimentista das políticas sociais. Dissertação de Mestrado em Serviço Social. João Pessoa, Universidade Federal da Paraíba, 2012. 226 p.

MAITO, Esteban Ezequiel - La transitoriedad histórica del capital. La tendencia descendente de la tasa de ganancia desde el siglo XIX. Revista: Razón y Revolución N²26, 2013, 31 p. 129-159.

MARX, Karl. O Capital: Crítica da Economia Política. Livro I. Vol.1, ed. Trad. Reginaldo Sant' Anna. Rio de Janeiro: Civilização Brasileira, 2002.

MARX, Karl. O Capital: crítica da economia política. Livro I, volume 2, Rio de Janeiro: Civilização Brasileira, 1998.

NETTO, José Paulo \& BRAZ, Marcelo. Economia Política: uma introdução crí-

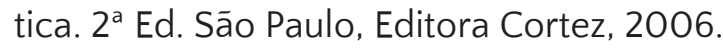

PINTO M. Barbosa; CERQUEIRA, Augusto Santiago. Reflexões sobre a pandemia da COVID-19 e o capitalismo. In: Revista Libertas / Universidade Federal de Juiz de Fora, Programa de Pós-graduação em Serviço Social, Curso de graduação em Serviço Social. - n.1 (abril, 2001), Juiz de Fora, ano 2020. pp. 38-52.

POCHMANN, Márcio. Nova Classe Média? O trabalho na base da pirâmide social brasileira. São Paulo: Boitempo, 2012.

ROBERTS, Michael. La Larga Depresión: Cómo ocurrió, por qué ocurrió y que ocurrirá a continuación. El Viejo Topo/Ediciones de Intervención Cultural. Barcelona, 2019.

ROBERTS, Michael. Blog. Disponible en: http://www.sinpermiso.info/Autores/Michael-Roberts. Acesso em: 25 abr. 2020. 
SCHUMPETER, Josepy Alois. Teoria do desenvo/vimento econômico: uma investigação sobre lucros, capital, crédito, juro e o ciclo econômico. São Paulo: Nova Cultural, 1997.

TAVARES, Maria Augusta. Os fios (in) visiveis da produção capitalista: informalidade e precarização do trabalho. São Paulo: Cortez, 2004.

\section{Notas}

1 Pós-doutora pela Universidad Complutense de Madrid. Professora Associada da Universidade Federal da Paraíba, Programa de Pós-Craduação em Serviço Social, Coordenadora do Grupo de Estudos e Pesquisa em Economia Política e Trabalho (GEPET), cadastrado no DGP/CNPq. ORCID 0000-0002-9366-3107. Contato: claudia.gomes@academico.ufpb.br

2 Mestra em Serviço Social pela Universidade Federal da Paraíba. Professora Substituta do Departamento de Serviço Social da UFPB (DSS) e pesquisadora do Grupo de Estudos e Pesquisas em Economia Política e Trabalho (GEPET/UFPB). ORCID 0000-0003-1680-3978. Contato: fabianalymajp@hotmail.com

3 Doutora em Serviço Social pela Universidade Federal do Rio Grande do Norte (UFRN). Membra do GEPET/UFPB. ORCID 0000-0003-2697-5466. Contato: lianacarvalhoss@hotmail.com

4 Cf.: Os autores que travam o debate: nos Estados Unidos, Reino Unido, França e Alemanha (David Harvey, Michael Roberts, Andrew Kliman, Fred Moseley), no Estado Espanhol (Arrizabalo Montoro, Diego Guerreiro, Mário Rosal, Javier Murilo). No Brasil (Reinaldo Carcanholo, Giovanni Alves, Murari Bovo, Eleutério Prado, entre outros).

5 O artigo é resultado do esforço analítico e acumulativo das pesquisas desenvolvidas no âmbito da Pós-graduação em nível de Mestrado e Pós-doutorado, os quais integram o Grupo de Estudos e Pesquisas em Economia Política e Trabalho (GEPET/UFPB) cadastrado no Diretório Geral de Pesquisadores/CNPq.

6 As políticas implementadas pelo Presidente dos Estados Unidos, Franklin D. Roosevelt, em resposta à Grande Depressão lançaram os fundamentos do estado keynesiano nos anos 1930.

7 Marx descreve como sendo "em todos os aspectos, a mais importante lei da economia política moderna e a mais essencial para se entender as relações mais difíceis. É a lei mais importante do ponto de vista histórico". Cf. Grundrisse: Manuscritos Econômicos de 1857-1858. Boitempo, 2011. p. 748. 
8 Para Michael Roberts (2019, p. 21), “um ponto de referencia mais específico seria, quando uma economia sofre uma grande recessão e todo indício de recuperação é tão leve que a tendência de crescimento anterior não chega a ser recuperada, ou se se recupera, levaria vários anos, uma década, ou inclusive mais".

9 "A financeirização do capitalismo contemporâneo deve-se a que as transações financeiras (isto é: as operações situadas na esfera da circulação), tornaram-se sob todos os sentidos hipertrofiadas e desproporcionais em relação à produção real de valores; tornaram-se dominantemente especulativas" (NETTO; BRAZ, 2006, pág. 232. Grifos no original).

10 "Sua lógica é a apropriação desenfreada da mais-valia, ou melhor, do lucro (o lucro especulativo); realiza assim, ou pelo menos pretende fazê-lo, os anseios derivados da própria natureza íntima do capital: o não compromisso com o valor de uso e, apesar disso, a autovalorização"(CARCANHOLO; NAKATANI, 2015, p. 54).

11 Cf.: Banco de Pagamentos Internacionais (BPI, 2014, p. 7) - 84 Informe Anual, jun. 2014. "[...] Apesar da euforia dos mercados financeiros, o investimento continua fraco. Em vez de aumentar a capacidade produtiva, as grandes empresas preferem recomprar ações ou embarcar em fusões e aquisições e, apesar das perspectivas de crescimento em longo prazo, a dívida continua a aumentar. Fala-se até de estagnação secular" (Tradução nossa). Disponível em: https://www.bis. org/publ/arpdf/ar2014_es.pdf. Acesso em 15 de mai. 2020.

12 Pesquisa Nacional por Amostra de Domicílios Contínua Divulgação Especial Medidas de Subutilização da Força de Trabalho. Disponível em:<https://agenciadenoticias.ibge.gov.br/media/com_mediaibge/arquivos/ff2505b84b22bdcbcdbf134ea9069e28.pdf > Acesso em: 30 mai 2020.

13 Nos indicadores do IBCE (2020) esses 4,8 milhões de trabalhadores se encontram em situação de desalento (desistiram de buscar emprego), portanto, estariam fora da força de trabalho potencial (desempregados).

14 Situação trabalhista na América Latina e no Caribe maio de 2020 Número 22: Trabalho em tempos de pandemia: desafios contra a doença de coronavírus (COVID-19). De acordo com as estimativas da OIT, o trabalho informal é a fonte de renda para muitos lares na América Latina e no Caribe, onde a taxa média de informalidade é de aproximadamente 54\%. Disponível: <https://www.cepal. org/es/publicaciones/45557-coyuntura-laboral-america-latina-caribe-trabajo-tiempos-pandemia-desafios frente > Acesso em 16 jun 2020.

15 Cf. Nações Unidas Brasil. Quase metade da força de trabalho global está sob risco de perder renda devida à Covid-19. Disponível em:<https://nacoesunidas.org/ quase-metade-da-forca-de-trabalho-global-esta-sob-risco-de-perder-renda-devido-a-covid-19-diz-oit/> Acesso em 16 jun 2020. 
16 Cf.: European Economic Forecast. Spring 2012, Commission Staff Working Document, Directorate-General for Economic and Financial Affairs, Bruselas. Disponível em: <https://ec.europa.eu/economy_finance/publications/european_economy/2012/pdf/ee-2012-1_en.pdf.> Acesso em: 12 de maio 2020.

17 Sancionado pela Lei $n^{\circ}$ 13.999/2020, com o objetivo de desenvolver e fortalecer os pequenos negócios. O programa prevê investimentos de 15,9 bilhões e uma linha de crédito até o limite de 30\% da receita bruta obtida em 2019, com a participação de diversos bancos públicos. Disponível: <http://www.portaldoempreendedor.gov.br/temas/credito/saiba-mais/pronampe> Acesso: 20 de jun 2020.

18 Disponivel em: < http://www.portaldoempreendedor.gov.br/estatisticas> Acesso em: 20 de Jun 2020.

19 Joseph Schumpeter (1997), considerado o principal teórico do empreendedorismo, em seu livro Teoria do Desenvolvimento Econômico, renova as promessas liberais ao defender a primazia do "espírito capitalista dos homens de negócios".

20 A CEPAL calcula os índices de pobreza e extrema pobreza com base em uma metodologia que estima a pobreza extrema como uma linha definida pela satisfação básica das necessidades de todos os seus membros, com base em uma seleção de alimentos que cobre os bens necessários para atender às necessidades nutricionais da população, levando em consideração seu nível de atividade física, hábitos de consumo e disponibilidade efetiva de alimentos e preços em cada país e área geográfica. A quantidade exigida pelas famílias para satisfazer as necessidades básicas não alimentares é adicionada ao valor dessa cesta básica para calcular o valor total da linha de pobreza. Já os percentuais de famílias vivendo nessas linhas é determinado pelo contraste entre o valor de ambas as linhas com a renda per capita total de cada família. A renda total da família é obtida somando-se os rendimentos auferidos por seus membros englobando trabalho, aposentadorias, pensões e outras transferências (CEPAL, 2019).

21 De acordo com o IBGE, na Síntese de indicadores sociais publicada no ano de 2019, a pobreza pode ser mensurada pelo critério de renda, referindo à 1,90 dólar por dia para estabelecer essa linha em países de baixa renda, conforme preconiza o Banco Mundial.

22 No Brasil, em particular, a crise econômica ganha uma feição particular pelo agravamento da situação política, através de um processo de impeachment concluído em 2016, pelo qual a era lulopetista foi sucedida pelo governo de Michel Temer e, em 2019, pelo de Jair Messias Bolsonaro, dando consecução incisiva ao receituário de Washington, diferente do neoliberalismo brando dos anos anteriores. Nesse sentido, visualizamos uma simbiose entre crise econômica e um mal-estar político com amplas consequências sociais. 
23 Márcio Pochmann (2012), em Nova classe média? alega que nos anos posteriores à crise de 2008 houve uma diminuição da pobreza e da desigualdade, o que levou alguns economistas a situarem tal contingente como uma nova classe média. Para o referido autor, o fato se explica através de uma elevação de renda per capita dos brasileiros pela expansão de ocupações no setor de serviços com remuneração de até 1,5 do salário mínimo, apesar de não desconsiderar o impacto das políticas de transferência de renda e a elevação do salário mínimo à época. Concordamos com o estudioso que, ao contrário do que foi cogitado, esta fração das classes trabalhadoras não conformam uma nova classe média, uma vez que mediante uma elevação no rendimento elevaram imediatamente o padrão de consumo, continuando, portanto, como classes populares.

24 Informações disponíveis em: https://auxilio.caixa.gov.br/\#/inicio. Acesso em jun. 2020. 